\section{El editor en Odontología Sanmarquina}

\section{The editor of Odontología Sanmarquina}

Manuel Antonio Mattos-Vela 1,a,c, Hilda Moromi Nakata 1,b,d

1 Universidad Nacional Mayor de San Marcos, Facultad de Odontología. Lima, Perú.

a Doctor en Estomatología.

${ }^{\mathrm{b}}$ Magíster en Administración de la Educación Universitaria.

c Editor general de la revista Odontología Sanmarquina.

${ }^{\mathrm{C}}$ Directora de la revista Odontología Sanmarquina.

\section{Correspondencia:}

Manuel Antonio Mattos-Vela

Correo electrónico: mmattosv@unmsm.edu.pe

Universidad Nacional Mayor de San Marcos, Facultad de Odontología. Calle

Germán Amézaga 375. Lima 1, Perú.

Recibido: 29/04/19

Aceptado: 07/05/19

Publicado: 05/06/19
El rol principal de un editor de una revista científica es publicar artículos de calidad y de relevancia a la comunidad a la cual va dirigida; teniendo para ello, el apoyo de revisores pares. Esta tarea implica: garantizar la validez y transparencia de los estudios que se publicarán, identificar sesgos metodológicos, detectar y controlar afirmaciones sobredimensionadas y estar atento a aspectos de ética y confidencialidad ${ }^{1}$.

La revista Odontología Sanmarquina, en el mes de abril de este año, acaba de renovar y fortalecer su Comité Editor. En el 2018, realizó una convocatoria abierta a la comunidad odontológica iberoamericana para integrar su equipo editor, se recibió 99 solicitudes provenientes de 13 países, de los cuales se invitó a algunos investigadores a integrarse dentro del Comité Consultivo y Comité Editor. Asimismo se realizaron invitaciones directas a algunos otros investigadores.

El equipo editor agradece la acogida que tuvo esta convocatoria y el interés mostrado por muchos investigadores en trabajar con Odontología Sanmarquina para publicar trimestralmente una revista de calidad.

En cuanto al Comité Editor, las personas invitadas tuvieron un periodo de entrenamiento, luego del cual se confirmó su integración al Comité. Las personas externas a nuestra institución que han ingresado al Comité Editor son: Luz Dahiana Alfaro Carballido (Perú),
María Antonieta Pérez Flores (Chile), Aron Aliaga Del Castillo (Brasil), Oscar Alberto Morales (Ecuador/Venezuela) y Juan Carlos Cuevas Gonzáles (México). El Dr. Morales es lingüista y colabora en calidad de consultor en temas de redacción y estilo. El Dr. Cuevas es miembro del Comité Consultivo; sin embargo, colaborará con nosotros como editor invitado.

A partir del presente número de la revista (2019; Vol. 22, Nro. 2), cada artículo publicado que ha pasado por un proceso de revisión por pares externos incluirá dentro de su primera página el nombre del editor responsable del seguimiento de ese manuscrito. Esta medida tiene como finalidad:

- Reconocer el trabajo realizado por el editor, quien invierte tiempo en el proceso de revisión del manuscrito, desde su recepción hasta su aprobación o rechazo, lo cual se realiza en coordinación con el editor general. La labor de un editor en Odontología Sanmarquina no es remunerada.

- Mejorar la calidad del artículo publicado, ya que el editor mostrará un mayor compromiso con el proceso de revisión del manuscrito.

- Transparentar el proceso editorial, lo cual es considerado una buena práctica dentro del campo editorial. 
- Atraer mayor número de personal de amplia trayectoria al equipo editor para participar de nuestra misión de difundir investigaciones con mayor nivel de exigencias hacia la comunidad odontológica iberoamericana ${ }^{2,3}$, acorde con el reconocimiento de esta importante labor.

Conscientes de las presiones externas que enfrenta un editor y para evitar posibles conflictos de interés ${ }^{4}$, la revista tendrá como política asignar siempre un manuscrito recibido a un editor de otra filiación institucional a la de los autores del trabajo, y de preferencia, de una nacionalidad distinta a la de los autores. No siempre será posible esto último, puesto que en esta etapa solo se contará con ocho editores responsables del seguimiento de manuscritos, cuatro internos (de la Universidad Nacional Mayor de San Marcos, Perú) y cuatro externos (de diferentes filiaciones institucionales y provenientes de otros tres países).

Los cambios que se están realizando buscan servir mejor a nuestra comunidad de lectores y proveerles de una literatura científica con altos niveles de confiabilidad. Siendo una revista en proceso constante de crecimiento el objetivo es seguir mejorando y para ello requerimos el apoyo de todos. Pueden comunicarse con nosotros a través de la sección "cartas al editor" o por mensajes enviados al correo electrónico o a las redes sociales de la revista. En nombre del Comité Editorial de Odontología Sanmarquina agradecemos los comentarios y recomendaciones que nos hagan llegar.

\section{Referencias bibliográficas}

1. Peiperl L. Keeping it real: A journal editor in clinic. PLoS Med. 2017;14(9):e1002394. DOI: 10.1371/journal. pmed.1002394.

2. Mattos-Vela MA, Cuadrao Zavaleta L. Seguimos avanzando [editorial]. Odontol Sanmarquina. 2017;20(1):34. DOI: 10.15381/os.v20i1.13535.

3. Mattos-Vela MA, Cuadrao Zavaleta L. Revista al servicio de la comunidad científica [editorial]. Odontol Sanmarquina. 2017;20(2):37-38. DOI: 10.15381/os. v20i2.13976.

4. Marcovitch H. Editors, publishers, impact factors, and reprint income. PLoS Med. 2010;7(10):e1000355. DOI: 10.1371/journal.pmed.1000355. 